O geopatrimónio foi considerado como um todo, ou referenciado apenas através das suas componentes, como é o caso dos patrimónios geológico e geomorfológico, ou dos elementos que representam este último, isto é, os geomorfossítios. Contudo, a promoção do património geomorfológico e dos geomorfossítios, inventariados e classificados em diferentes áreas e a diferentes escalas, foi sempre relacionada com o desenvolvimento geoturístico dessas áreas. Para alcançar o desenvolvimento sustentável local, usando abordagens geoturísticas, alguns autores recomendaram a elaboração de mapas geoturísticos, que podem ser concebidos utilizando distintos métodos, conteúdos e símbolos.

\title{
BIBLIOGRAFIA
}

Rocha D, Sá AA (Coords.) (2011) Proceedings of the International Congress of Geotourism, AROUCA2011.Arouca, Portugal.

Rodrigues M L (2011) The scope of geotourism. In Rocha D, Sá, AA (Coords.), Proceedings of the International Congress of Geotourism, AROUCA2011 (.), Arouca, Portugal: 101-104.

Rodrigues M L, Freire E (eds.) (2010) Proceedings of the International Conference on Geoheritage and Geotourism, Lisbon. APGeoturand CEG-UL, Lisboa, Portugal.
Rodrigues M L, Castaldini D, Serrano E (Coords.) (2011) GeoJournal of Tourism and Geosites, special issue, 2/2011, IV(8). http://gtg.webhost.uoradea.ro/

Tourtellot J (2011) National Geographic, Daily News, 17 November 2011.http://newswatch. nationalgeographic.com/2011/11/16/unesco $\%$ E2\%80\%99s-\%E2\%80\%9Cgeoparks\% E2\%80\%9D-embrace-geotourism/?mid=52 [Acedido em 18 de Novembro de 2011].

\section{ENCONTRO ANUAL DA ASSOCIAÇÃO AMERICANA DE GEÓGRAFOS 2011 RETROSPECTIVA TEMÁTICA E APRENDIZAGENS}

O encontro anual da associação americana de geógrafos é uma das maiores reuniões da ciência geográfica ao nível mundial. A sua organização em formato semanal, intercala sessões de apresentação, com painéis de debate, workshops, feira de emprego em geografia,

1 Núcleo TERRiTUR (Turismo, Cultura e Território), Centro de Estudos Geográficos, IGOT; albino.sara@gmail.com; diana-almeida@campus.ul.pt

2 Núcleo MOPT (Modelação, Ordenamento e Planeamento do Território), Centro de Estudos Geográficos, IGOT; joaofumega@gmail.com 
com visitas de estudo temáticas, dentro e fora da cidade que acolhe o evento, entre outras actividades de carácter profissional, académico e lúdico.

Esta plataforma de difusão do conhecimento, tem a vantagem de reunir profissionais de geografia e de outras áreas do saber, motivando assim a participação de um grande número de pessoas provenientes de todo o mundo. A presença de académicos, cientistas e outras figuras de renome que acompanham as sessões plenárias e também os painéis de debate, permite aprofundar questões específicas e a discussão dos mais recentes temas investigados, bem como os problemas da actualidade.

Realizou-se em Seattle, nos dias 11 a 16 de Abril, a edição de 2011 do encontro anual da Associação Americana de Geógrafos. Estiveram presentes aproximadamente 7000 pessoas de cerca de 60 países. A temática que esteve subjacente foi "Geography in the Changing Worlds of Higher Education: Opportunities and Challenges", e constituiu também a sessão de abertura.

É importante destacar a ocorrência de três sessões sobre a temática da noite, inéditas no contexto dos encontros da AAG - "Nightscapes: Geographies of Urban Nights". Na edição de 2010, em Washington, o CEG esteve representado por João Fumega que foi apresentar o projecto NOITe, motivando o surgimento desta temática como sessão autónoma.

\section{RETROSPECTIVA TEMÁTICA}

\section{Gestão de zonas húmidas e áreas costeiras}

Ocorreram 113 sessões sobre as questões que integram a gestão costeira, nomeadamente o turismo, o planeamento, o estudo da biogeografia dos ambientes marítimos e costeiros. De forma a sintetizar destacam-se quatro apresentações que abrangem estas temáticas: metodologias de gestão; roteiros turísticos em frentes de água; turismo e urbanização em áreas costeiras.

As sessões sobre Coastal Tourism dividiram-se entre tendências, conflitos e sustentabilidade; e usos do solo e o planeamento dos lazeres. Na primeira sessão foram abordados alguns dos produtos turísticos em zonas costeiras e a sua sustentabilidade, na segunda sessão, voltou-se a incidir sobre metodologias de gestão de espaços recreativos em frentes de água. Dois investigadores da Universidade da Georgia utilizaram de forma combinada os sistemas de informação geográfica e os sistemas de alerta pela internet. Através de inquéritos aos residentes e utilizadores da ilha, foto interpretação com base em fotografias aéreas de ilhas barreira, dados históricos sobre as marés e uso do solo, foi possível prever quais as melhores alturas para aceder à praia como turista, colocando essa informação online para ser descarregada como uma aplicação. Este trabalho permitiu ainda estudar a evolução dos efeitos das marés em diferentes partes da ilha, avaliando as áreas de erosão e de acreção, com efeitos imediatos para os residentes. Outra das apresentações tentava recuperar os vários percursos em torno do Lago Michigan, com o objectivo de agregar os pré-existentes roteiros terrestres (pedonais e cicláveis) e os roteiros aquáticos (canoagem e vela) e construir simultaneamente um pacote de turismo aventura sustentável e, através de um baixo custo de implementação, incluir o turista/visitante na preservação do lago. Por último, o turismo e urbanização em áreas costeiras (Projecto SECOA - Solutions for Environmental Contrasts in Coastal Areas) partiu de duas áreas de estudo analisadas no projecto (Costa de Caparica e Albufeira), tendo introduzido o turismo e a urbanização numa óptica 
de mudança de usos turísticos. Foram utilizados dados estatísticos de 1991 e 2001 que permitiram retratar a evolução urbano-turística. A metodologia baseou-se na definição de uma faixa de 500 metros a montante da linha de costa sobre ortofotomapas, permitindo o zonamento detalhado em áreas focadas no planeamento de segundas residências, acessibilidades e parqueamento, concessão de praias, resorts turísticos, entre outros. Concluiu-se este ser um poderoso instrumento de gestão do espaço turístico, podendo ser útil no melhoramento e impedimento da privatização dos espaços, incorporando uma função de monitorização.

\section{Mobilidade e turismo}

As sessões intituladas Mobilities of Everyday Life coordenadas por Alan Lew da University of Arizona e apoiadas pelo Recreation, Tourism and Sport Speciality Group da AAG, contaram com uma forte presença interdisciplinar, tendo como objectivo contribuir para a criação de um novo paradigma de discussão das mobilidades, que tenha em atenção a análise das experiências, práticas e significâncias culturais da mobilidade aliadas à análise geográfica. Foram organizadas quatro sessões por David Butz e Nancy Cook da Brock University. Devido à grande heterogeneidade de investigadores de diversas formações académicas presentes nestas sessões, a questão da discussão epistemológica tornou-se uma constante, tendo havido uma premência do uso de metodologias qualitativas de análise, como base das investigações apresentadas nas comunicações, uma vez que a coordenação desta sessão deu ênfase a trabalhos que focassem o domínio dos efeitos sociais da mobilidade no território. Evidenciaram-se apresentações acerca das mobilidades pendulares de trabalhadores do sector do turismo no Japão, onde o Prof. Chris McMorran da National University of Singapura discutiu o papel social das mulheres Nakai. Foram também apresentados trabalhos de investigação acerca da capacidade de carga de zonas comerciais urbanas de cidades centrais europeias, como decorrente da rede de transportes e da sua atractividade como destino turístico interno e local de lazer. Numa dimensão oposta, o Prof. Antti Honkanen, Director do Centro de Estudos de Turismo da University of Eastern Finland discutiu a questão das razões que levam os indivíduos à rejeição da viagem turística, debatendo-se a dicotomia entre a incrementação da mobilidade quotidiana em oposição à viagem pontual. A esfera da análise das políticas públicas correlacionada com a mobilidade física de pessoas e representações foi um dos vectores de discussão da sessão onde participou Sara Albino, a qual apresentou os resultados preliminares de uma investigação a decorrer acerca da relação entre as políticas europeias de educação, juventude e desporto da União Europeia nas últimas duas décadas e o surgimento de um mercado de turismo interno Europeu dirigido a uma faixa etária variável das populações juvenis. No conjunto, estas sessões ao discutirem assuntos que evidenciam as questões da imobilidade como contraponto da mobilidade, as quais são apontadas como centrais na vida social contemporânea, tentaram responder à seguinte questão: em que medida é que o movimento de indivíduos, informação, bens e capitais constituem novos padrões sociais e constituem redes formais e informais?

\section{Comunidades sustentáveis}

A sessão intitulada "Sustainable Communities" (12 Abril) foi o culminar de duas sessões anteriores sobre esta temática, organizadas conjuntamente pela Wilfrid Laurier Univer- 
sity e pela Simon Fraser University tendo contado com a moderação da Prof. Alison BlayPalmer. O primeiro orador, Prof. Terry Marsden (Cardiff School of City and Regional Planning, Sustainable Places Research Institute), discursou sobre o tema "Building Capability Skills". De forma a estabelecer uma ferramenta conceptual para a reconstituição e revitalização dos espaços de génese rural-urbana sugere a análise das esferas dos recursos de consumo e produção, módulos de paisagem, nichos sócio tecnológicos, mecanismos de transição e contestação assim como configurações de expressão espacial. Foca a importância das zonas rurais e sua capacidade de resiliência para o equilíbrio das zonas urbanas, capacidade essa que deve ser potencializada através da construção ou reconstrução de capacidades com base nas mais-valias intrínsecas de cada uma destas áreas. O Prof. Julian Ajyeman (Tufts University) com a comunicação "Sustainable Communities: environmental quality and human equality" por seu turno, abordou as questões da qualidade ambiental e igualdade. Afirmou que promovendo a igualdade como princípio a sociedade está a contribuir para uma melhor qualidade do ambiente urbano, focando noções de multiculturalismo, bem-estar e felicidade, justiça nas questões da agricultura urbana e acesso à alimentação e da justiça espacial à escala urbana mas sobretudo do bairro e rua. O terceiro orador convidado, Prof. Roger Keil (York University) discursou sobre os grandes desafios que se colocam às comunidades sustentáveis, nomeadamente a crescente mudança de escalas e deterritorialização a que se assiste na maioria das cidades, fruto de padrões de vivências cada vez mais irregulares, o que em última análise provoca o surgimento de várias comunidades que não se limitam ao espaço do habitar mas sim a todo o espaço de interacção do indivíduo. É a seu ver essencial focar os esforços de promoção de sustentabilidade nos subúrbios, entendê-los como um conjunto heterogéneo que se manifestam em territórios com diferentes características, e a partir destes agir, reencontrando aqui as noções de comunidade, urbanidade e sustentabilidade e construindo uma nova realidade urbana. O quarto orador, Prof. Mark Roseland (Simon Fraser University, $S F U$ ), com a comunicação intitulada "Sustainability as Community Development" veio apresentar a fundação da International Network of Local Sustainability Researchers, que será suportada por um projecto de investigação, e terá uma revista "Journal of Local Environment", assim como previsto um congresso, e uma plataforma web. No fundo, vai de encontro às expectativas e necessidades de unir a variada investigação que tem sido feita nesta área, num grupo constituído por experts, esperando-se assim que se retire o melhor do que está a ser feito, evitando sobreposições e potenciando o tema através da colaboração entre diferentes centros e investigadores.

As quatro sessões, incidindo sobre perspectivas díspares, foram bastante esclarecedoras, pois focam quatro pontos essenciais para a afirmação de comunidades mais sustentáveis: a importância dos espaços rurais para a manutenção da estrutura ecológica de suporte às zonas urbanas, a equidade como valor essencial de uma comunidade, a intervenção nos subúrbios como forma de tornar as zonas urbanas mais coesas e integradoras e por fim a necessidade da criação de redes na investigação que é feita sobre a temática, como forma de potenciar a produção científica, e assim produzir conhecimento estruturante, moderno e que possa ser replicado no terreno pelos agentes que aqui intervêm.

\section{APRENDIZAGENS}

A visita de estudo com a temática "Vancouver: seaking the sustainability" decorreu entre os dias 9 e 11 de Abril de 2011, com estadia na cidade de Vancouver no dia 9 e no dia 
11 à tarde e com estadia em Whistler, no dia 10 e 11 de manhã. A partida para o resort turístico de montanha (Whistler) teve lugar no dia 10 de Abril e contou com a supervisão científica de Alison Gill (Simon Fraser University, SFU). No local, a visita de estudo foi acompanhada por Peter Williams ( $S F U$ ) especialista em turismo sustentável, tendo estudado e colaborado com o poder local durante vários anos no caso específico de Whistler. A visita realizou-se a pé em toda a estância, atravessando as diferentes fases de construção do resort, tendo como pano de fundo os recentes jogos olímpicos de inverno de 2010, ali realizados. $\mathrm{O}$ enfoque foi dado essencialmente à sua função turística, recreativa e desportiva, tentando estabelecer a ponte entre a organização, os serviços e os usos de Whistler e a sua sustentabilidade enquanto resort turístico. Nesta última fase, reuniu-se um grupo de discussão composto por membros da Câmara Municipal de Whistler, responsáveis pela última fase do projecto e também pela gestão urbana. Apesar das medidas que se pretendem cumprir para alcançar a sustentabilidade, não se pode deixar de questionar o seu próprio funcionamento enquanto destino internacional, com todos os custos económicos e ambientais associados, onde o seu acesso se faz por automóvel ou transporte rodoviário, com uma densidade de utilização e pressão sobre os recursos naturais, que são simultaneamente a marca de exclusividade deste resort turístico de montanha.

Considerando a questão da segurança e combate ao terrorismo um aspecto central da política norte-americana e canadiana e sendo Seattle uma cidade de fronteira a $200 \mathrm{~km}$ de Vancouver na região da British Columbia, a AAG organizou uma visita de estudo denominada "US-Canada Border" que decorreu no dia 12 de Abril, a qual foi organizada pela Embaixada do Canadá. A iniciativa foi conduzida pelo respectivo Adido Cultural em conjunto com o Centro de Estudos de Migrações e Fronteiras da Universidade de Washington. A actividade centrou-se na visita às instalações do posto de fronteira Canadiano, pelo Director do Centro de Operações de Combate ao Crime. A visita centrou-se na apresentação da estratégia conjunta de combate à criminalidade entre os governos norte-americano e canadiano, nomeadamente através da criação de um cartão de identificação transfronteiriço. Discutiram-se os principais problemas de comunicação política entre os estados envolvidos, assim como as acções de melhoramento dos serviços de fronteira, nomeadamente através do recurso aos sistemas de informação geográfica na operacionalização do combate à criminalidade. Decorreu também uma visita de estudo ao Aquário de Seattle, legado da primeira fase da reabilitação da zona ribeirinha da cidade e apresentando a problemática da Pacific Coast Highway (via rápida de 1970) que corta o acesso pedonal e visual à frente de água. Foram apresentados planos para renovar a imagem da cidade que incluem a demolição do troço da via que cruza Seattle. 